\section{Capacity Building in e-Health and Health Informatics: A Review of the Global Vision and Informatics Educational Initiatives of the American Medical Informatics Association}

\author{
D. E. Detmer \\ Senior Advisor, American Medical Informatics Association, Bethesda, MD, USA \\ Professor Emeritus and Professor of Medical Education, University of Virginia, Charlottesville, VA, USA
}

"The greatest danger in times of turbulence is not the turbulence; it is to act with yesterday's logic."

- Peter Drucker

Substantial global and national commitments will be required for current healthcare systems and health professional practices to become learning care systems utilizing information and communications technology (ICT) empowered by informatics. The challenge is multifaceted and involves a vision that moves from silos of activities to integrated systems. Essential elements include a sufficient ICT infrastructure, evolving health care processes based on evidence and harmonized to local cultures, a fresh view toward educational preparation, sound and sustained policy support, with all of it anchored by ongoing applied research and development.

Increasingly, leaders are aware that ICT empowered by informatics must be an integral part of their national and regional visions. This paper sketches out the elements of what is needed in terms of objectives and some steps toward achieving them, including progress made to date by the American and International Medical Informatics Associations working separately as well as collaborating through members across the globe to conceptualize informatics capacity building in order to play major roles in manifesting the vision in reality in low resource nations in par- ticular. While IMIA and its global members pursue independently a number of other important educational initiatives, these activities will not be the focus of this article. The AMIA Global Partnership Program will be discussed in terms of its origins and progress to date.

\section{Background}

A review of global health initiatives undertaken by governments, the United Nations, charities and philanthropic organizations including foundations, trusts, and other groups shows efforts which are 'siloed', e.g., they focus solely on a specific disease, region, or group [1]. Further, the information infrastructure in most nations or regions is highly variable. Communications technology is emerging in most settings but availability, reliability and cost are important issues. Well-trained health workers are insufficient in aggregate numbers and geographic distribution to meet needs and expertise relating to ICT and informatics is even more variable.

Disease patterns are shifting somewhat as these economies develop. Typically, there are admixtures of a number of social determinants of health among them poor nutrition and dangerous environments due to civil unrest or poor governance, plus issues relating to adequate shelter, meaningful employment, and a wide range of diseases. 
Diseases are often compounded; for example, HIV/AIDS is present in combination with tuberculosis, other infectious diseases, and rising rates of vehicular trauma.

Inclusive of telemedicine and electronic health records with some decision support, ICT is emerging as a key part of securing advances in both personal care and public health. Nations are beginning to make ICT/informatics a part of their health strategies at the same time there is growing interest in harmonizing public health and personal health programs to transition from silos of activity to systems that can crosscommunicate and ideally integrate.

A few centers of excellence are emerging in low resource countries across the world. These are typically universities but in some instances the center may be within a government or external agency. The World Health Organization working with others has worked hard to communicate the importance of e-Health to these centers and other influential entities within nations and regions. The e-Health activity has suffered from a lack of sufficient focus and targeted priorities. Arguably, more attention has been spent discussing concepts than focusing on education and training in the basics of applied clinical informatics and related policy essentials at the level of public health and national leadership. In fairness, progress has occurred and motivations remain high despite the recent global economic downturn.

Through recent efforts of the Rockefeller Foundation, including a critical series of meetings at its Bellagio Center in July and August of 2008, a coherent review of both challenges and opportunities for making eHealth connections both global and local occurred with work agendas being developed [1]. Reports relating to this meeting were recently published in the journal Health Affairs including additional reflections from Susan Dentzer, editor [2].

Most recently, an additional global meeting sought to move these agendas forward. The Prince Mahidol Award Forum on Global Health Information was held in Bangkok, Thailand in late January 2010 (see http://www. pmaconference.org/). Workforce capacity has been only one part of these activities but there is widespread agreement that an appropriately trained workforce is a critical dimension if sustained progress is to be achieved. AMIA is committed to contributing its fair share in helping to address this challenge.

AMIA has benefitted from the contributions of its international members for many years. Indeed, fifty nations are represented in its membership. In addition, AMIA and it members have actively collaborated with IMIA and its MedInfo meetings over the years. However, beginning six years ago, AMIA began to formulate an explicit strategy to engage with others to improve health outcomes through the use of informatics in developing nations. One key strategy to accomplish this worthy goal involves the education and training of clinical informaticians and also through the support of improving the level of informatics knowledge, skills, and attitudes in both formal and informally trained health workers - both clinicians and public health professionals. Some insights relating to the educational challenge from colleagues collaborating in this work were recently reported by Hersh et al [3].

AMIA is convinced that electronic health records (EHRs) and EHR systems are essential to both the planning and delivery of high quality health care in both low and high resource settings. With support from the Bill and Melinda Gate Foundation and the Rockefeller Foundation, substantial plans have been made and implementation of educational and training offerings should begin either this year or next. The plan is to engage partnerships among global colleagues and a few nations or regions and expand as time and financial re-

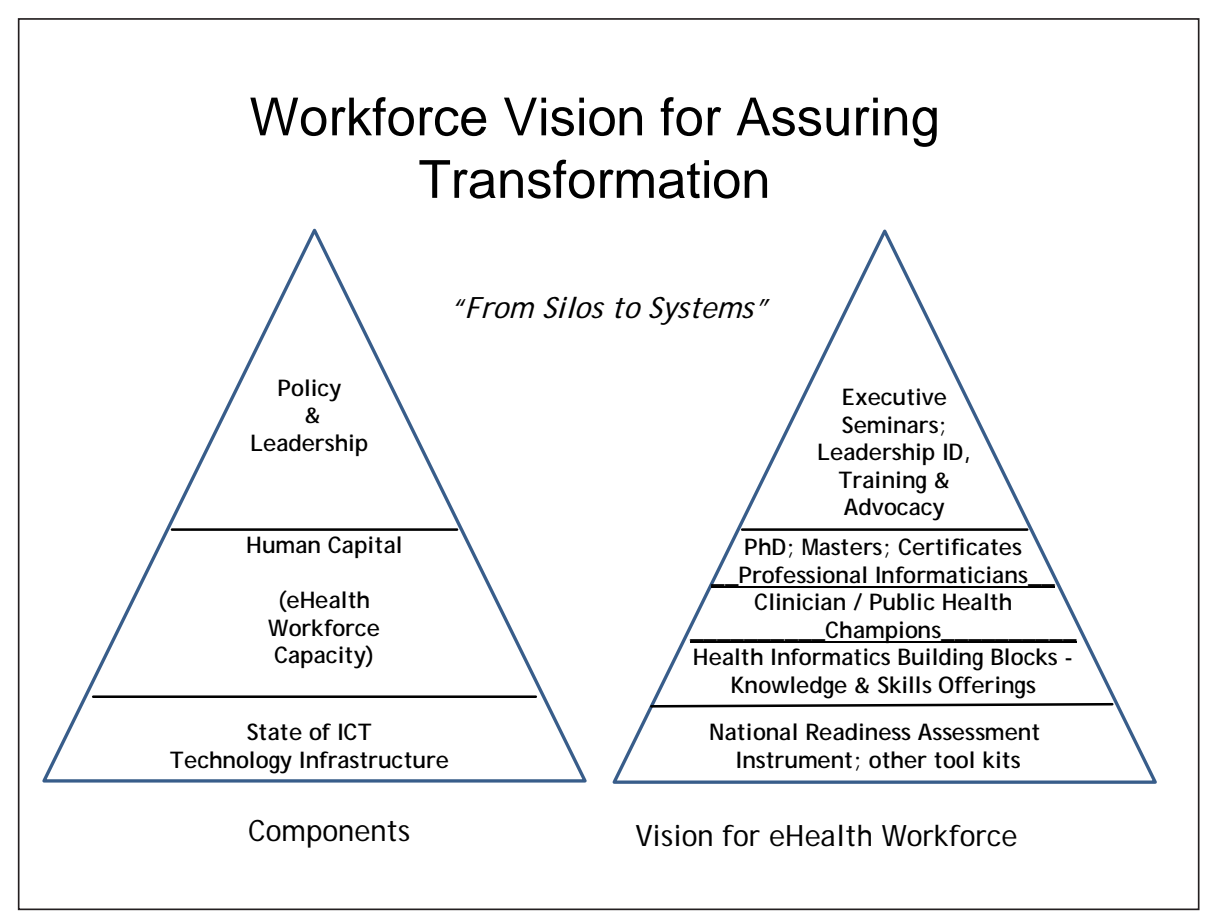

Fig. 1 e-Health vision for moving from silos of care to integrated systems. On the left are illustrated the components required in environments for effective care utilizing EHRs and EHR systems in nations and regions. On the right are the components of the e-Health educational strategy that will be required to address the workforce challenge (adapted by Detmer from the Bellagio meeting). 
sources allow. Reflections from contributors to the AMIA strategy were reported recently by Tierney et al [4]. Greater details follow later in this paper but the general model emerged from the successful e-Capacity meeting at Bellagio in 2008. See Figure 1.

To move from silos of activity to systems of care entails meeting knowledge gaps in and among key players both leaders and workers at a number of levels within systems. Governments must play an essential role if there is to be sustained support. Relevant seminars and related learning experiences and materials are needed for policy makers and public health officials and the learning experiences should relate to both population and public health perspectives as well as care issues for individuals.

Despite being an oversimplification, a triangle was used for the model rather than a square to suggest that fewer individuals will require training at the policy level when compared to the level of health care and public health. All elements within the schematic are considered to be essential to any given region's plan and each plan will require appropriate analysis for planning purposes. Oversight of actions taken and ongoing evaluation should be part of the plan as resources allow. Every effort should be made to engage education and training to some degree at all levels so a comprehensive regional plan is created. The detailed plan needs to based upon local assessments that also relates realistically to opportunities and cultural realities.

The next largest group includes all those engaged in the direct delivery of care. This includes clinicians who offer leadership as 'champions' that help doctors and nurses use EHRs and EHR systems effectively and efficiently. Some of their leadership role is educating others to be effective clinical leaders or 'champions' in their own practice settings. More is said about training 'champions' later. Another critical group needing basic knowledge and skills are informally trained caregivers. Indeed, the learning needs of these care workers, patients, the general public and their representatives will vary depending on the given environment. Priorities on who needs training and when are likely to vary from region to region.

Finally, there is the level of the ICT technology and its support. EHR technicians are critical for functioning EHRs and they work in a wide array of environments. In some environments, EHRs may not be available, and if so, more effective uses of paper can be helpful for guiding care. Of course, facilitating the use of cell phones and telemedi-cine for care and education is important. Finally, there is the hardware and software infrastructure itself. Knowledge and skills are needed to evaluate environments and support implementation of appropriate systems in such environments. Evolution toward better systems makes this an unending challenge.

There are heavy requirements for leadership at all levels if progress is to occur, so a process identifying individuals for training will need to incorporate some admixture of nomination by others as well as self-selection to have the greatest likelihood of success in terms of seeing action 'on the ground'. Training at all levels should include at least some elements of 10cally relevant leadership skills. In addition to executive level seminars that give policy and care system leaders insights into key aspects of EHRs and EHR systems [4,5], policy issues such as data integrity and security, use of best evidence, likely costs, and a review of the experiences of others in similar circumstances should be included [6]. It is even possible that some content for such seminars may reflect issues that emerged at a recent AMIA policy meeting focusing on the USA [7]. In addition, seminars for 'influentials', that is, informal leaders who have access to top leaders, needs to be part of the vision and the strategy since they may be critical to adoption of new policies and approaches.
The next three levels of education and training focuses on the knowledge, skills, and attitudes critical for successful implementation and use of ICT in public health, health care delivery, and maintenance of the ICT infrastructure. At the highest level of expertise are degree and/or certificate programs for fully trained applied clinical informaticians working mostly within university setting or other centers of excellence, or working outside such settings but with direct linkages to such centers. Two levels of ICT/informatics training are needed being delivered either as short courses and/or certificate programs for practicing health professionals, including doctors, nurses, pharmacists, and public health experts, etc. One set of training materials needs to focus primarily on individuals who serve as local 'champions' at work in those delivery sites with sufficient numbers of staff to need a 'go-to' individual to set priorities, offer direction and leadership, and assure successful implementation and use of ICT in these environments. Very short courses covering basic skills are needed as well for all health care workers who will use EHRs, including informally trained health workers at the front line of care including those in isolated villages.

Clearly, a basic level of ICT/ informatics training is essential for all practicing health professionals. A model for a common inter-professional informatics curriculum for the USA was recently developed by the Academic Strategic Leadership Council of AMIA and this information is available upon request from AMIA [8]. It would need to be adapted for other settings. According to this model, within the basic education of all entry level health professionals, e.g., physician nurse, pharmacist, dentist, public health practitioner, etc, should be basic knowledge, skills and attitudes with respect to: 1) working in teams, 2) improving quality of care, 3 ) practicing evidence-based care, 4) putting the patient at the center of care, and 5) utilizing informatics for both informa- 
tion and communications technology. Three levels of education and training are envisioned as the student progresses through their educational preparation. First, the student needs to be able to recognize the content at a basic level of recognition (awareness). Second level competence would include showing that there is actual understanding of the curriculum (semantics). At the third level, they should be able to possess the attitudes essential for successful use of the knowledge and skills (pragmatics).

At least seven domains of competency may be involved and these include: 1) communication, 2) documentation, 3 ) ethics of access and uses of person-specific health information, 4) information seeking \& utilization, 5) patient engagement, 6) problem solving, and 7) systems approach to clinical practice.

AMIA has a pilot grant from the Rockefeller Foundation to create some model educational content to be known collectively as "Health Informatics Building Blocks", or HIBBs. This content will involve a number of courses focusing on relevant basic knowledge, skill development, and/or attitudes. A good example of a HIBB that AMIA has developed over the past five years for use in the USA is Digital Patient Record Certification (see http:// www.dprcertification.com/, accessed 12 March 2010. This is a course with a validated examination that contains the essential knowledge and skills needed to use a computer that can show the user person-specific health information. Principles of privacy, confidential, security, and good practice behaviors are included as well as relevant legal requirements to meet compliance.

In addition, AMIA has developed an program known as AMIA 10x10 which seeks to give sufficient information to interested clinicians so that they can become effective clinical 'champions' for leading implementation of EHRs in their environments [9]. Within the past three years, AMIA has collaborated with sites in Argentina and Singapore to create an international version adapted to local needs. The courses offered outside the USA are referred to as $\mathbf{1 1 0 \times 1 0}$ and others are welcome to become engaged [10] More can be found relating to the $10 \times 10$ developments at the AMIA website. (see http:// www.amia.org/10x10, accessed 12 March 2010)

At the level of professional preparation for applied clinical informaticians, AMIA has developed both core competencies and training requirements toward what is likely to become a subspecialty certification process in North America for physicians and thereafter other master or doctorate level health professionals $[11,12$, 13,14]. Some competencies were first described by IMIA without a specific focus on applied clinical informatics [15]. Whether and when such developments in low resource nations would be appropriate is not immediately clear. It is likely that programs for clinical 'champions', e.g., local leaders, will be certificate programs but in some environments master's and even doctoral level education may be appropriate in biomedical and health informatics, including public health informatics. $10 \times 10$ offerings in public health informatics, translational bioinformatics and research infor-matics are also part of the AMIA $10 \times 10$ portfolio. Public health informatics competencies have recently been developed for the US context [16]. Of course, nursing informatics program for applied nursing infor-matics have been in existence for many years as well as certification [17]. AMIA hopes to develop an Advanced Inter-professional Informatics Certification for the nursing, pharmacy, dentistry, and physicians who prefer this route to the medical subspecialty certification route described above.

The strategy also includes a need for HIBBs and 'instruments' to allow regions and localities to know how to assess their own levels of readiness for EHRs, EHRs systems, distance education and/or telemedicine. The Health
Metrics Networks have some models that parallel aspects of what is intended here [18]. It is likely that a number of 'tool kits' would be very helpful but this is the focus for further work.

Additional meetings have served to maintain momentum and progress. Examples include the Geneva Health Forum [19] and others that are forthcoming, especially IMIA's MedInfo scheduled for September 2010 in Cape Town, South Africa. see http:// www.medinfo2010. org/ [20].

\section{Conclusions}

The challenges involved in realizing the vision described here are substantial and one can only be humbled by the difficulties they represent. Only continued application and reflective practice, evaluative research and refinement will result in success across the wide variety of settings needing improvements in health outcomes. The goal is worthy and the prospects are exciting. Biomedical and health informaticians are committed to increase the numbers of well trained people knowledgeable in informatics and ICT. Such expertise is essential to better health across the globe.

\section{References}

1. From Silos to Systems: An Overview of eHealth's Transformatics Power. Making the eHealth Connection: Global Partnerships, Local Solutions. Rockefeller Foundation Report/Bellagio Center Conference Series/January 13, 2010/ Publications. See http://www.rockefellerfoundation.org/news/ publications/from-silos-systems-overview-ehealth, accessed 9March2010.

2. Dentzer S: E-Health's Promise for the Developing World. Health Affairs 2010; 29:229. See http:// content.healthaffairs.org/cgi/content/full/29/2/229, accessed 11March2010.

3. Hersh WR, Margolis A, Quirós F, Otero P, Building a health informatics workforce in developing countries. Health Affairs 2010,29:274-77.

4. Seebregts CJ, Mamlin BW, Biondich PG, Fraser HS, Wolfe BA, Jazayeri D, et al. The OpenMRS implementers network. Int J Med Inform 2009;78 (11):711-20. 
5. Geissbuhler A, Bagayoko CO, Ly O. The RAFT network: five years of distance continuing medical education and tele-consultations over the Internet in French-speaking Africa. Int J Med Inform 2007:76:351-6.

6. Tierney WM, Kanter AS, Fraser HSF, Bailey C: A Tookit for E-Health Partnership in Low-Income Nations. Health Affairs 2010, 29:268-73.

7. Bloomrosen M, Detmer DE. Informatics, Evidencebased Care and Research; Implications for National Policy: A Report of an American Medical Informatics Association Health Policy Conference. JAMIA 2010, 17:115-23.

8. AMIA Academic Strategic Leadership Council proposal (William Stead, Chair), 2009 (available upon request).

9. Hersh W, Williamson J, Educating 10,000 informaticians by 2010: the AMIA $10 \times 10$ program. Int J Med Inform 2007;76:377-82.

10. Otero P, Hersh W, Luna D, López-Osornioa A, Quiros FGB, Langlois E, et al. Translation, implementation and evaluation of a medical informatics distance learning course for Latin America. MEDINFO 2007 - Proceedings of the Twelfth World Congress on Health (Medical) Informatics. 2007. Brisbane, Australia: IOS Press. CD-ROM P421.

11. Detmer DE, Munger B, Holmes J, Lumpkin J, Williamson J: Editorial: Defining the Medical Subspecialty of Clinical Informatics. JAMIA 2009;16:167-8.

12. Gardner RM, Overhage JM, Steen EB, Munger BS, Holmes JH, Williamson JJ, Detmer DE, for the AMIA Board of Directors. Core Content for the Subspecialty of Clinical Informatics. JAMIA 2009;16:153-7.

13. Safran C, Shabot MM, Holmes JH, Steen, EB, Lumpkin, JR, Detmer, DE for AMIA Board of Directors: Program Requirements for Fellowship Education in the Subspecialty of Clinical Informatics. JAMIA 2009;16:158-66.

14. Detmer DE, Munger BS, Lehmann CU: Medical Informatics Board Certification: History, Current Status, and Predict Impact on the Medical Informatics Workforce. Applied Clinical Informatics. 2010;1:11-18

15. Douglas JV, Hovenga EJ. Health and Medical Informatics Competencies: call to participate in updating the IMIA recommendations. Methods Inf Med 2002:41(2):86-8.

16. CDC: Competencies for Public Health Informaticians. See http://www.cdc.gov/ InformaticsCompetencies/, accessed 12 March 2010.

17. American Nurses Credentialing Center. Informatics Nursing. Available online at http:// www.nursecredentialing.org/NurseSpecialties/ Informatics.aspx, accessed 11 March 2010.

18. Health Metrics Network framework, see http:// www.who.int/healthmetrics/documents/framework/ en/index.html, accessed 24 May 2010.

19. Geneva Health Forum, see http:// www.genevahealthforum.org/, accessed 12March 2010.

20. MedInfo 2010, see http://www.medinfo2010.org/, accessed 12 March 2010.

\section{Acknowledgments}

The author acknowledges the contributions and support of IMIA colleagues involved in the meeting in Bellagio, those relating to the wide variety of AMIA programs and initiatives referenced in this paper, in particular AMIA 10x10 and HIBBs and applied clinical informatics specialty certification. Finally, the AMIA staff and advisory group members of the AMIA Global Partnership Program deserve a special mention as do other members of the AMIA staff. Support from the Bill and Melinda Gates Foundation, Rockefeller Foundation, and the Robert Wood Johnson Foundation has been critical to the progress noted here and is gratefully acknowledged. All views expressed are solely the responsibility of the author.

Correspondence to:
D.E. Detmer, MD, MA
5245 Browns Gap Turnpike
Crozet, VA, USA
Tel: + 14348231766
Fax : + 14348232615
E-mail: detmer@virginia.edu or detmer@amia.org

